\title{
Nanoscale
}

Check for updates

Cite this: Nanoscale, 2021, 13, 10092

\section{Atomic insights into the oxygen incorporation in atomic layer deposited conductive nitrides and its mitigation by energetic ions $\uparrow$}

\author{
Saurabh Karwal, ${ }^{*} \neq^{\mathrm{a}}$ Bora Karasulu, (D) * $\neq^{\mathrm{b}}$ Harm C.M. Knoops, ${ }^{\mathrm{a}, \mathrm{c}}$ Vincent Vandalon, ${ }^{\mathrm{a}}$ \\ Wilhelmus M.M. Kessels $\mathbb{B D}^{a}$ and Mariadriana Creatore (D)*a
}

\begin{abstract}
Oxygen is often detected as impurity in metal and metal nitride films prepared by atomic layer deposition (ALD) and its presence has profound and adverse effects on the material properties. In this work, we present the case study of $\mathrm{HfN}_{x}$ films prepared by plasma-assisted ALD by alternating exposures of $\mathrm{CpHf}$ $\left(\mathrm{NMe}_{2}\right)_{3}$ and $\mathrm{H}_{2}$ plasma. First, we identify the primary source of $\mathrm{O}$ contamination in the film. Specifically, we find that the extent of $\mathrm{O}$ incorporation in $\mathrm{HfN}_{x}$ films is determined by the flux of background $\mathrm{H}_{2} \mathrm{O} / \mathrm{O}_{2}$ residual gases reaching the $\mathrm{HfN}_{x}$ surface during the ALD process and leads to the formation of $\mathrm{Hf}-\mathrm{O}$ bonds. Then, we report on the decrease in the concentration of $\mathrm{Hf}-\mathrm{O}$ bonds in the film upon application of an external radiofrequency (rf) substrate bias during the $\mathrm{H}_{2}$ plasma step. The experimental work is accompanied by first principles calculations to gain insights into the $\mathrm{O}$ incorporation and its mitigation upon the impingement of energetic ions on the surface. Specifically, we find that the dissociative binding of $\mathrm{H}_{2} \mathrm{O}$ on a bare $\mathrm{HfN}$ surface is highly favored, resulting in surface $\mathrm{Hf}-\mathrm{OH}$ groups and concomitant increase in the oxidation state of $\mathrm{Hf}$. We also show that energetic cations $\left(\mathrm{H}^{+}, \mathrm{H}_{2}{ }^{+}\right.$and $\left.\mathrm{H}_{3}{ }^{+}\right)$lead to the dissociation of surface $\mathrm{Hf}-\mathrm{OH}$ bonds, $\mathrm{H}_{2} \mathrm{O}$ formation, and its subsequent desorption from the surface. The latter is followed by reduction of the $\mathrm{Hf}$ oxidation state, presumably by $\mathrm{H}^{\bullet}$ radicals. The atomic-level understanding obtained in this work on $\mathrm{O}$ incorporation and its abstraction are expected to be crucial to prevent $\mathrm{O}$ impurities in the $\mathrm{HfN}_{x}$ films and contribute to the fabrication of other technologically relevant low resistivity ALD-grown transition metal nitride films.
\end{abstract}

Received 17th December 2020 Accepted 25th May 2021

DOI: 10.1039/d0nr08921d

rsc.li/nanoscale

\section{Introduction}

Atomic layer deposition (ALD) has emerged as the method of choice for the synthesis of ultra-thin, uniform and highly conformal layers, required in the fabrication of advanced nanoscale device architectures. ${ }^{1-4}$ At the same time, control over the film properties in terms of chemical composition and microstructure is highly important. When specifically referring to the metal and metal nitride films prepared by ALD, oxygen is often detected as impurity. ${ }^{5-7}$ An interesting class of materials to evaluate the effect of oxygen contamination is one

\footnotetext{
${ }^{a}$ Department of Applied Physics, University of Technology Eindhoven, 5600MB, P.O. Box 513, Eindhoven, Netherlands. E-mail: s.karwal@tue.nl, m.creatore@tue.nl ${ }^{b}$ Department of Chemistry, University of Warwick, Gibbet Hill Road, Coventry, CV4 7AL, UK. E-mail: bora.karasulu@warwick.ac.uk

'Oxford Instruments Plasma Technology, North End, Bristol, BS49 4AP, UK

$\dagger$ Electronic supplementary information (ESI) available: ALD review table, ALD recipe schematic, $\mathrm{H}_{2} \mathrm{O}$ flux determination, DFT computational details and $\mathrm{HfN}_{x}$ surface models, binding energy of plasma species, energetic ion impingement and surface redox reactions. See DOI: 10.1039/d0nr08921d

$\$$ These authors contributed equally.
}

of conductive transition metal nitride (TMN) films, such as $\operatorname{TiN}_{x}, \operatorname{TaN}_{x}, \mathrm{MoN}_{x}, \mathrm{HfN}_{x}$. In fact, oxygen contamination can be directly related to the decrease in electrical conductivity, as illustrated in the literature overview for various TMN films (ESI section A, Table S1†). ${ }^{8-28}$ In particular, Musschoot et al. and Langereis et al. reported on the inevitable oxygen incorporation in $\operatorname{TiN}_{x}$ and $\operatorname{TaN}_{x}$ films and suggested residual $\mathrm{H}_{2} \mathrm{O}$ in the reactor background and/or process gases as potential sources of oxygen contamination in the films. ${ }^{21,22}$ Furthermore, Krylov et al. demonstrated that also the erosion of the quartz tube can lead to oxygen impurities whereas Rayner et al. did an extensive and systematic study of the possible origins of the impurities. ${ }^{20,24}$ However, these observations have not been followed by in-depth analysis of the surface reactivity of TMN films towards $\mathrm{H}_{2} \mathrm{O} / \mathrm{O}_{2}$.

Recently, we have reported on the growth of the conductive phase of hafnium nitride ( $\delta$ - $\mathrm{HfN})$ by adopting $\mathrm{CpHf}\left(\mathrm{NMe}_{2}\right)_{3}$ as $\mathrm{Hf}(\mathrm{Iv})$ precursor and $\mathrm{H}_{2}$ plasma as co-reactant. ${ }^{13,14}$ We observed that the $\operatorname{HfN}_{x}$ films contained 20 at.\% oxygen. ${ }^{14}$ Furthermore, due to the formation of Hf-O bonds, a low Hf(III) oxidation state fraction of 0.65 was detected, contributing to a 
rather high film resistivity of $0.9 \Omega \mathrm{cm} .{ }^{14}$ Moreover, we have also reported a decrease in the film resistivity by two orders of magnitude down to $3.3 \times 10^{-3} \Omega \mathrm{cm}$ upon the application of an external radiofrequency (rf) substrate bias during the $\mathrm{H}_{2}$ plasma step with a time-averaged potential value ( $\left.V_{\text {bias }}\right)$ of $-130 \mathrm{~V} .^{13}$ This resulted from a decrease in oxygen content to below 2.0 at.\% and a correlated increase in the $\mathrm{Hf}(\mathrm{III})$ fraction up to $0.82 .^{13}$ These results suggest a correlation between the decrease in oxygen content in the films and the increase in the average energy of incident ions $\left(E_{\text {ion }}\right)$. However, the mechanism of the suppression of oxygen content enabled by energetic ions was not explored.

In this work, we first elucidate the primary source of oxygen incorporation in the film and study the dependence of oxygen content as a function of the total ALD cycle time. We find a gradual increase in the oxygen content when the ALD cycle time is increased. Subsequently, we demonstrate a gradual decrease in the density of $\mathrm{Hf}-\mathrm{O}$ bonds in the $\mathrm{HfN}_{x}$ films with an increase in $E_{\text {ion }}$, enabled by the application of external $\mathrm{rf}$ substrate bias. By means of first-principles density functional theory (DFT) calculations, we provide an atomistic insight into the kinetics of chemisorption of gaseous $\mathrm{H}_{2} \mathrm{O} / \mathrm{O}_{2}$ on the pristine $\mathrm{HfN}$ surface that leads to formation of surface $\mathrm{Hf}-\mathrm{OH}$ groups. Subsequently, we show that energetic cations in the $\mathrm{H}_{2}$ plasma trigger the dissociation of surface $\mathrm{Hf}-\mathrm{OH}$ bonds and lead to $\mathrm{H}_{2} \mathrm{O}$ formation, followed by its desorption. In addition, we hypothesize that the $\mathrm{H}^{*}$ radicals in the $\mathrm{H}_{2}$ plasma reduce $\mathrm{Hf}(\mathrm{Iv})$ to $\mathrm{Hf}(\mathrm{III})$ subsequent to $\mathrm{H}_{2} \mathrm{O}$ desorption, in-line with our previous report. ${ }^{13}$ The atomic-level understanding of the oxygen incorporation and the underlying mechanism of its removal provided here is expected to be key in devising efficient approaches for preventing oxygen impurities in the ALD-grown metal nitride and metal films.

\section{Methods}

The plasma-assisted ALD process of $\mathrm{HfN}_{x}$ films was carried out in an Oxford Instruments FlexAL ALD reactor that is equipped with an inductively coupled remote plasma (ICP) source with an alumina dielectric tube. ${ }^{6,29}$ A base pressure of $10^{-6}$ Torr was achieved in the reactor chamber using a turbomolecular pump before every deposition. Briefly, the metalorganic $\mathrm{Hf}(\mathrm{Iv})$ precursor $\mathrm{CpHf}\left(\mathrm{NMe}_{2}\right)_{3}$ was used and an $\mathrm{H}_{2}$ plasma served as the reducing co-reactant. The details of the recipe can be found elsewhere. ${ }^{14}$ An ALD cycle under saturation conditions comprised of a $\mathrm{CpHf}\left(\mathrm{NMe}_{2}\right)_{3}$ pulse of $4 \mathrm{~s}$ and $\mathrm{H}_{2}$ plasma exposure of $10 \mathrm{~s}$, while keeping the purge steps of 2 s after every half cycle (ESI section B, Fig. S1 $\dagger$ ). An external rf substrate bias was applied during the $\mathrm{H}_{2}$ plasma exposure. As a result of bias application, a time-averaged negative potential with respect to ground develops at the substrate $\left(V_{\text {bias }}\right){ }^{13,30}$ The magnitude of the developed $V_{\text {bias }}$ was tuned by varying the applied rf power transmitted to the substrate holder as previously reported. ${ }^{13}$ Furthermore, as a result of negative substrate potential, the average energy of exclusively the cationic species in the plasma is enhanced by accelerating them towards the HfN surface. The substrate holder was heated to $450{ }^{\circ} \mathrm{C}$ which corresponds to an actual substrate temperature of $340{ }^{\circ} \mathrm{C} .{ }^{13} \mathrm{Si}(100)$ with a diameter of $100 \mathrm{~mm}$ and with $450 \mathrm{~nm} \mathrm{SiO}{ }_{2}$ atop was used as the substrate on which $\sim 30 \mathrm{~nm}-$ $40 \mathrm{~nm} \mathrm{HfN}_{x}$ films were deposited. Using thick $\mathrm{SiO}_{2}$ (insulating and transparent film) enables an accurate measurement of resistivity and optical constants of the $\mathrm{HfN}_{x}$ films.

$\mathrm{X}$-ray photoelectron spectroscopy (XPS) measurements were performed using a Thermoscientific K-Alpha KA1066 system equipped with a monochromatic $\mathrm{Al} \mathrm{K} \alpha(h \nu=1486.6 \mathrm{eV})$ source in order to study the chemical bonds and the oxidation states of the elements present in the film. XPS measurements were carried out by first sputtering the $\mathrm{HfN}_{x}$ film for $500 \mathrm{~s}(8 \mathrm{~nm}-$ $10 \mathrm{~nm}$ ) by $\mathrm{Ar}^{+}$ions with low energy of $200 \mathrm{eV}$. This was done in order to eliminate the contribution of surface impurities from the first few layers of $\mathrm{HfN}_{x}$ film and to ensure the measurement of chemical composition of the bulk $\mathrm{HfN}_{x}$ film precisely. Rutherford backscattering spectrometry (RBS) was performed using $1900 \mathrm{keV}^{4} \mathrm{He}^{+}$ions (Detect99) with two detectors at scattering angles of $170^{\circ}$ and $150^{\circ}$ in order to study the chemical composition of the $\mathrm{HfN}_{x}$ layers.

All electronic structure calculations were done using the projector augmented wavefunction (PAW) $)^{31,32}$ as implemented in Vienna $A b$ Initio Simulation Package (VASP, v.5.3.5). ${ }^{33-36}$ Generalized gradient approximation (GGA) to $\mathrm{DFT}^{37,38}$ was used jointly with the Perdew-Burke-Ernzerhof (PBE) exchange correlation functional. ${ }^{39,40}$ DFT(PBE)-D3 corrections with Becke-Jonson damping ${ }^{41}$ were employed to account for van der Waals interactions on an empirical basis (see ESI section $\mathrm{C} 1 \dagger$ for further computational details).

\section{Results}

Our initial experiments were focused on the investigation of the primary source of oxygen incorporation in the $\mathrm{HfN}_{x}$ films. This was probed by adding a pump-down step following the $\mathrm{H}_{2}$ plasma exposure in order to bring the reactor down to the vacuum base pressure (ESI section B, Fig. S1†). The duration of the pump-down step was varied from $0 \mathrm{~s}$ to $80 \mathrm{~s}$, thereby increasing the total ALD cycle time from $20 \mathrm{~s}$ to 100 s. This additional pump-down step exposed the $\mathrm{HfN}_{x}$ surface only to the residual gases in reactor background. Fig. 1a shows the $O$ 1s XPS spectra of the $\mathrm{HfN}_{x}$ films as a function of total ALD cycle time. A gradual increase in $\mathrm{O} 1 \mathrm{~s}$ peak associated to $\mathrm{Hf}-\mathrm{O}$ bonds is observed when increasing the total ALD cycle time, leading to a steady decrease in $\mathrm{Hf}$ (III) fraction from $0.65 \pm 0.02$ to $0.47 \pm 0.02$. This result suggests that oxygen content in the $\mathrm{HfN}_{x}$ layers is determined by the total flux of residual $\mathrm{H}_{2} \mathrm{O} / \mathrm{O}_{2}$ gases in the reactor background reaching the $\mathrm{HfN}_{x}$ surface. In every ALD cycle, this pristine $\mathrm{HfN}_{x}$ surface is exposed to the vacuum conditions for a relatively long time, making it susceptible to oxidation even at a vacuum base pressure of $10^{-6}$ Torr. Relevantly, Kroll et al. showed that the oxygen incorporation 

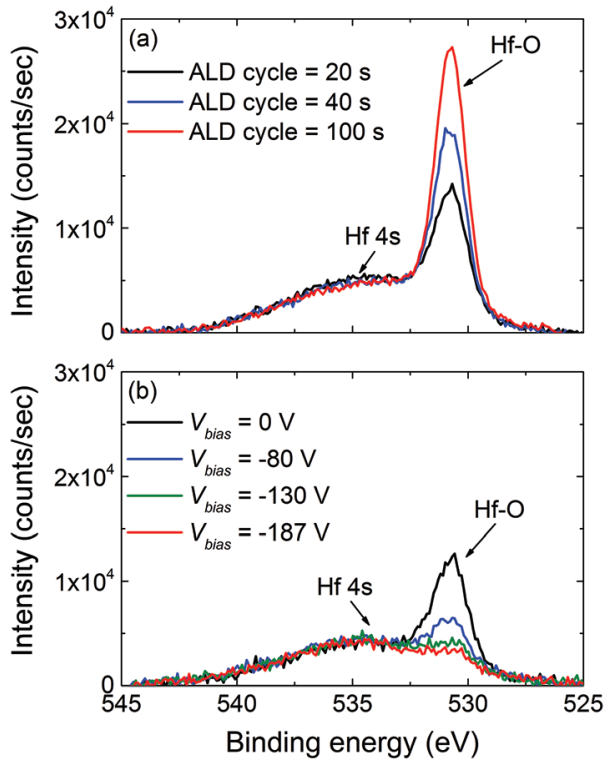

Fig. $1 O$ 1s XPS spectra for the (a) $\mathrm{HfN}_{x}$ films prepared with grounded substrate $\left(V_{\text {bias }}=0 \mathrm{~V}\right)$ showing an increase in the $O 1 \mathrm{~s}$ peak associated to $\mathrm{Hf}-\mathrm{O}$ bonds as a function of ALD cycle time. The difference in ALD cycle time is due to an extension of the pump-down time of the reactor. (b) $\mathrm{HfN}_{x}$ films grown at various values of $V_{\text {bias }}$ illustrating a steady decrease in the $\mathrm{O} 1 \mathrm{~s}$ peak associated to $\mathrm{Hf}-\mathrm{O}$ bonds from 20.1 at.\% to $<2.0$ at.\% upon increasing the $V_{\text {bias }}$ from $0 \mathrm{~V}$ to $-130 \mathrm{~V}$ and above. The corresponding film resistivity decreased from $0.9 \Omega \mathrm{cm}$ at $V_{\text {bias }}=0 \mathrm{~V}$ to $9.7 \times 10^{-3} \Omega \mathrm{cm}$ at $V_{\text {bias }}=-80 \mathrm{~V}$ and to $3.3 \times 10^{-3} \Omega \mathrm{cm}$ at $V_{\text {bias }}=$ $-130 \mathrm{~V}^{13}$

in a-Si: $\mathrm{H}$ films prepared by plasma-enhanced CVD was enhanced at lower deposition rates. ${ }^{19}$ The reactor outgassing, i.e. release of residual gases, was identified as one of the primary reason for oxygen contamination. ${ }^{19}$ The lower the deposition rate of a-Si: $\mathrm{H}$ films, the more important is the flux of outgassed residual gases. In our case, in order to illustrate that even very low background pressures can lead to significant oxygen incorporation in the film, the flux of $\mathrm{H}_{2} \mathrm{O}$ molecules impinging on the $\mathrm{HfN}_{x}$ surface was calculated using the Hertz-Knudsen equation (see ESI section $\mathrm{B} \dagger$ ). Using these calculations, an oxygen content of $39 \%$ is deduced assuming an $\mathrm{H}_{2} \mathrm{O}$ partial pressure of $10^{-8}$ Torr and a sticking probability of 1 for ALD cycle time of $20 \mathrm{~s}$. This calculation reveals that a significant $\mathrm{O}$ content in the film can result even from a very low background $\mathrm{H}_{2} \mathrm{O}$ partial pressure.

The effect of application of external rf substrate bias on the oxygen content in the $\mathrm{HfN}_{x}$ films was subsequently investigated. The $\mathrm{HfN}_{x}$ films were prepared using a $\mathrm{H}_{2}$ plasma exposure of $10 \mathrm{~s}$ (no pump-down step) and the magnitude of $V_{\text {bias }}$ was gradually increased from $0 \mathrm{~V}$ to $-187 \mathrm{~V}$ during the $\mathrm{H}_{2}$ plasma half cycle. Fig. 1b shows the $\mathrm{O} 1 \mathrm{~s}$ XPS spectra as a function of the value of $V_{\text {bias. }}$. Interestingly, the $O 1 \mathrm{~s}$ peak associated to $\mathrm{Hf}-\mathrm{O}$ bonds significantly decreased upon increasing the $V_{\text {bias }}$ from $0 \mathrm{~V}$ to $-80 \mathrm{~V}$, suggesting a decrease in the density of Hf-O bonds. Moreover, an increase in the $V_{\text {bias }}$ to
$-130 \mathrm{~V}$ or higher led to a saturation in decrease of $\mathrm{Hf}-\mathrm{O}$ peak intensity, yielding an oxygen content below 2.0 at.\% as determined by RBS. ${ }^{13}$ Energetic ions may lead to the physical sputtering of oxygen. In the case of sputtering, a decrease in the areal density of nitrogen atoms is also expected to occur in parallel. In contrast, we reported an increase in the areal density of nitrogen atoms per cycle from $0.71 \pm 0.03$ atoms per $\mathrm{nm}^{2}$ at $V_{\text {bias }}=0 \mathrm{~V}$ to $1.53 \pm 0.08$ atoms per $\mathrm{nm}^{2}$ at $V_{\text {bias }}=-130 \mathrm{~V}^{13}$ This cannot be simply explained by sputtering. Therefore, a preferential abstraction of oxygen (and containing groups) is expected as a result of the impingement of energetic ions on the surface of growing film. The seminal works of Sigmund and Steinbrüchel show that $c a$. 10 times higher ion energy values than the bond energy value is required in order to dissociate molecular bonds, due to the inefficient transfer of the ion energy to the film surface. ${ }^{42,43}$ Following this, Kanarik et al. recently reported on the requirement of $\mathrm{Ar}^{+}$ions with an $E_{\text {ion }}$ of $c a .50 \mathrm{eV}$ in order to enable the dissociation of $\mathrm{Si}-\mathrm{Si}$ bonds with a bond energy of $2.3 \mathrm{eV}$ in order to facilitate the atomic layer etching of $\mathrm{Si}^{44,45}$ In our case, assuming a similar energy transfer factor, an $E_{\text {ion }}$ of $\sim 90-100 \mathrm{eV}$ seems adequate to dissociate the surface $\mathrm{Hf}-\mathrm{O}$ bonds with a high bond energy of $\sim 5.4 \mathrm{eV}$, as computed using DFT calculation as will be shown later.

In order to gain insights into the oxygen incorporation in the $\mathrm{HfN}_{x}$ films and its mitigation upon delivery of energetic ions to the surface, detailed DFT calculations were carried out. To this end, the dissociative binding of $\mathrm{H}_{2} \mathrm{O}$ and $\mathrm{O}_{2}$ on a bare HfN surface was simulated. Three $\delta$-HfN models were generated for DFT simulations: one $\mathrm{HfN}(200)$ surface with equivalent $\mathrm{N}$ and Hf- termination and two HfN(111) surface with either Hfor $\mathrm{N}$ - termination (see ESI section $\mathrm{C} 2$, Fig. $\mathrm{S} 2 \dagger$ for the discussion on HfN surface termination). The DFT calculations indicate that the surface energies for $\operatorname{HfN}(200)$ and $\operatorname{HfN}(111)$ surfaces are $10 \mathrm{eV} \mathrm{nm}^{-2}$ and $15 \mathrm{eV} \mathrm{nm}^{-2}$, respectively. This result suggests that $\mathrm{HfN}(200)$ surface is likely the predominant orientation. ${ }^{13}$ This is in-line with our experimental observations on the growth of polycrystalline $\delta$ - $\mathrm{HfN}_{x}$ films, with the co-existence of $\operatorname{HfN}(200)$ and $\operatorname{HfN}(111)$ orientations at $V_{\text {bias }}=0 \mathrm{~V}$ and $V_{\text {bias }}=$ $-130 \mathrm{~V}^{13}{ }^{13}$ For brevity, we discuss here the results for the case of $\mathrm{HfN}(200)$ surface, whereas similar results for $\mathrm{Hf}(111)$ surface can be found in the ESI (section D2 $\dagger$ ).

$A b$ initio molecular dynamics (AIMD) simulations were performed to generate canonical (NVT) ensembles at $1000 \mathrm{~K}$ in vacuum environment, using 1 fs time step for a set of at least 3.0 ps trajectories. The model system used for bare $\mathrm{HfN}(200)$ surface contained $32 \mathrm{Hf}$ and $32 \mathrm{~N}$ atoms on the topmost surface (ESI, section $\mathrm{C} 2 \dagger$ ). A total of $16 \mathrm{H}_{2} \mathrm{O}$ molecules were placed atop the $\mathrm{HfN}(200)$ surface, providing a surface coverage ratio of one $\mathrm{H}_{2} \mathrm{O}$ molecule per two surface $\mathrm{Hf}$ sites (i.e. $\mathrm{Hf}: \mathrm{O}=$ $2: 1$ ). MD simulations suggest that following a dissociative binding process, $\mathrm{H}_{2} \mathrm{O}$ molecules bind exclusively to $\mathrm{Hf}$ atoms, leading to the formation of $\mathrm{Hf}-\mathrm{OH}$ bonds (Fig. 2), supporting the XPS results of Fig. 1a. Similar results were obtained for Hf (111) surface (see ESI section D2, Fig. S3 $\uparrow$ and the related discussion). 

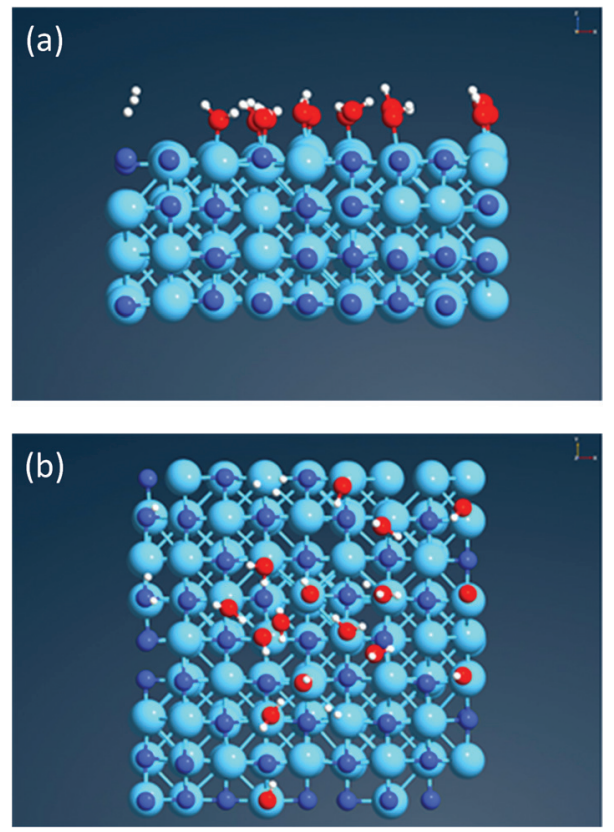

Fig. 2 (a) Side-view and (b) top-view snapshot from the AIMD simulation of the thermal hydroxylation of bare $\mathrm{HfN}(200)$ surface. A total of $16 \mathrm{H}_{2} \mathrm{O}$ molecules were added to provide a coverage ratio of $\mathrm{Hf}: \mathrm{O}=$ 2 : 1. Color code: cyan: $\mathrm{Hf}$; blue: $\mathrm{N}$; red: $\mathrm{O}$; white: $\mathrm{H}$.

Furthermore, the dissociative binding of $\mathrm{H}_{2} \mathrm{O}$ molecules could proceed via two routes. The first involves the combination of two $\mathrm{H}_{2} \mathrm{O}$ molecules to yield $\mathrm{a}_{2}$ molecule, with the two $-\mathrm{OH}$ groups easily binding on two $\mathrm{Hf}(\mathrm{III})$ sites (eqn (1)). The second route involves the binding of one $-\mathrm{OH}$ group at the Hf-site, whereas the additional $\mathrm{H}$ is transferred to the neighbouring $\mathrm{N}$-site (eqn (2)).

$$
\begin{gathered}
2 \mathrm{Hf}(\mathrm{III}) *+2 \mathrm{H}_{2} \mathrm{O}_{(\mathrm{g})} \rightarrow 2 \mathrm{Hf}(\mathrm{III})^{\delta+}-\mathrm{OH}^{\delta-} *+\mathrm{H}_{2(\mathrm{~g})} \\
\mathrm{Hf}(\mathrm{III}) *+\mathrm{N} *+\mathrm{H}_{2} \mathrm{O}_{(\mathrm{g})} \rightarrow \mathrm{Hf}(\mathrm{III})^{\delta+}-\mathrm{OH}^{\delta-} *+\mathrm{N}-\mathrm{H} *
\end{gathered}
$$

*denotes surface species, whereas partial charges are represented by $\delta+, \delta$-. Partial charges are only present to the surface as $\mathrm{Hf}(\mathrm{III})-\mathrm{N}$ bonds are present in the bulk.

AIMD simulations suggest route 1 is most likely to occur, as concluded from the released $\mathrm{H}_{2}$ molecules and the absence of amine groups $(\mathrm{N}-\mathrm{H})$ (see Fig. 2 and ESI section D2, Fig. $\mathrm{S} 3 \dagger$ for snapshots from the relevant $\mathrm{MD}$ trajectories). For a more quantitative comparison, the climbing-image nudged elastic band (CI-NEB) method was utilized for concerted binding of two $\mathrm{H}_{2} \mathrm{O}$ molecules on a pristine $\mathrm{HfN}(200)$ surface following each pathway. Fig. 3 shows the resulting minimum energy paths (MEPs) revealing that unlike the second pathway (eqn (2)), which has a high activation energy $\left(E_{\mathrm{a}}=0.28 \mathrm{eV}\right)$, the first one (eqn (1)) is both kinetically and thermodynamically highly feasible $\left(E_{\mathrm{a}}=0.11 \mathrm{eV}\right.$ and $\left.\Delta E=-2.05 \mathrm{eV}\right)$, in-line with the above AIMD results. Furthermore, it should be noted that by assuming the pre-exponential factors in the Arrhenius equation to be similar in magnitude for the two reactions, at
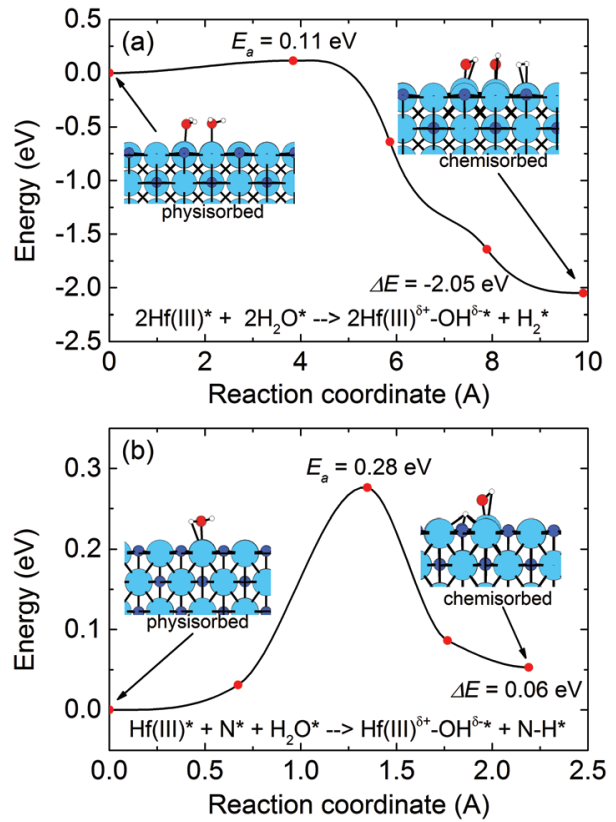

Fig. 3 DFT/PBE-D3 level minimum-energy paths (MEPs) for the dissociative binding of $\mathrm{H}_{2} \mathrm{O}$ molecule(s) on the bare $\mathrm{HfN}(200)$ surface following the pathways as described in (a) eqn (1) and (b) eqn (2). The physisorption energies (with respect to the isolated $\mathrm{HfN}$ surface and $\mathrm{H}_{2} \mathrm{O}$ molecule) are -0.88 and -0.80 eV per $\mathrm{H}_{2} \mathrm{O}$ adsorbate, respectively, indicating a high surface sticking probability. Color code: cyan: Hf; blue: $\mathrm{N}$; red: O; white: $\mathrm{H}$.

$25{ }^{\circ} \mathrm{C}$ the difference in kinetic barrier translates into a rate constant 750 times higher for route 1 than route 2 .

Based on the AIMD and NEB results, it can be concluded that the binding of $\mathrm{H}_{2} \mathrm{O}$ on a pristine $\mathrm{HfN}$ surface is expected to proceed via route 1 , leading to surface $\mathrm{Hf}-\mathrm{OH}$ groups. The overall reaction for hydroxylation of bare HfN surface can thus be written as in eqn (1), whereas the corresponding hypothesized redox half reactions are discussed in the ESI (section $\mathrm{D} 2$, eqn (S3)-(S7)†).

Furthermore, the low $E_{\mathrm{a}}$ agrees well with the easy incorporation of oxygen in the $\mathrm{HfN}_{x}$ films prepared by plasma-assisted ALD with the grounded electrode as discussed earlier. It is worth mentioning that the reverse reaction (i.e. associative desorption of $\mathrm{H}_{2} \mathrm{O}$ ) is energetically unfeasible, involving high energy barriers and high endothermicity. The latter conclusion falls in line with the high bond energy of $\sim 5.4 \mathrm{eV}$ for surface $\mathrm{Hf}-\mathrm{OH}$ bonds, as computed using DFT calculations (see section $\mathrm{D} 2$, eqn (S8) $\dagger$ and the related discussion), rendering surface $-\mathrm{OH}$ groups thermodynamically stable.

Related to this point, DFT calculations predict a strong initial physisorption of the $\mathrm{H}_{2} \mathrm{O}$ molecules $(-0.88$ and -0.80 eV per $\mathrm{H}_{2} \mathrm{O}$ molecule), which implies a low desorption rate as compared to the dissociative binding of $\mathrm{H}_{2} \mathrm{O}$ on the surface with low activation energies (see above). Taken together a high surface sticking probability is predicted, whereas the entropic contributions play a minor role in the sticking probability due to the small size of the adsorbate. 
Alongside the background $\mathrm{H}_{2} \mathrm{O}$, the dissociative binding of gaseous $\mathrm{O}_{2}$ on $\mathrm{HfN}$ surface was also investigated (see ESI section D3 for detailed discussion, Fig. S4†). The dissociative binding of $\mathrm{O}_{2}$ on HfN surface is found to be kinetically hindered $\left(E_{\mathrm{a}}=0.25 \mathrm{eV}\right)$ when compared to chemisorption of $\mathrm{H}_{2} \mathrm{O}$.

The effect of energetic ions on surface functionalization was investigated next. First, the binding energies of distinct species in a $\mathrm{H}_{2}$ plasma towards surface - $\mathrm{OH}$ group was determined using static $a b$ initio DFT calculations. Here, the plasma species have not been assigned any initial velocity (i.e. the species are without kinetic energy) and only the chemical affinity of different plasma species towards the surface $-\mathrm{OH}$ groups is probed. For simplicity, the $\mathrm{HfN}(200)$ surface was assumed to be fully hydroxylated (with $\mathrm{Hf} / \mathrm{O}=1: 1$ ), along with a fully oxygenated one (with $\mathrm{Hf} / \mathrm{O}=2: 1$ ) for comparison purposes (see ESI section E1, Fig. S5 $\uparrow$ for further discussion). Bader charge analysis ${ }^{46,47}$ reveals that the binding of $32-\mathrm{OH}$ groups leads to an increase in the total charge of HfN slab by ca. $16 e$, in-line with the partial oxidation of $\operatorname{Hf}\left(\right.$ III) to $\mathrm{Hf}(\mathrm{III})^{\delta+}$ (see note ${ }^{48}$ for a detailed discussion).

Based upon the experimental work of Sode et al., ${ }^{49} \mathrm{a} \mathrm{H}_{2}$ plasma discharge is expected to contain $\mathrm{H}^{-}, \mathrm{H}^{+}, \mathrm{H}_{2}^{+}$and $\mathrm{H}_{3}^{+}$ ions and $\mathrm{H}^{\cdot}$ radicals species. Table 1 summarizes the computed binding energies of all the possible $\mathrm{H}_{2}$ plasma species with the surface -OH groups at the PBE-D3 level. Furthermore, the corresponding reaction products as a result of their binding with surface - $\mathrm{OH}$ groups are also reported. The products are determined as a part of structure optimization procedure. Furthermore, since the plasma species were not given kinetic energy, the reaction products formed remain chemisorbed on the surface in their intermediate forms (for example, $\mathrm{H}^{+}$ions lead to formation of surface $\mathrm{Hf}-\left[\mathrm{H}_{2} \mathrm{O}\right]^{+}$ bonds).

It can be concluded that the cationic species $\left(\mathrm{H}^{+}, \mathrm{H}_{2}{ }^{+}\right.$and $\mathrm{H}_{3}{ }^{+}$) show the highest affinity for the surface $-\mathrm{OH}$ groups. Furthermore, the cationic species are predicted to form $\mathrm{H}_{2} \mathrm{O}$ as a product upon reacting with surface $-\mathrm{OH}$ groups. In contrast, the anionic $\left(\mathrm{H}^{-}, \mathrm{H}_{2}{ }^{-}\right.$and $\left.\mathrm{H}_{3}{ }^{-}\right)$and neutral $\left(\mathrm{H}, \mathrm{H}_{2}\right.$ and $\left.\mathrm{H}_{3}\right)$ species are (energetically) reluctant to react with the surface $-\mathrm{OH}$ groups. The anionic and neutral species in the $\mathrm{H}_{2}$ plasma

Table 1 DFT/PBE-D3 level binding energies $\left(E_{\mathrm{b}}\right)$ of various hydrogencontaining plasma species on a hydroxylated HfN surface and the type of volatile product(s) being formed. The most reactive species (i.e. cations), their $E_{\mathrm{b}}$ and type of products are given in bold. Only a single adsorbent species is considered for computing the $E_{\mathrm{b}}$ of each adsorbing species

\begin{tabular}{lll}
\hline Species & $E_{\mathrm{b}}{ }^{a}[\mathrm{eV}]$ & Reaction product(s) \\
\hline $\mathrm{H}^{-} / \mathrm{H}^{-} \mathbf{H}^{+}$ & $0.05 /-1.81 /-2.25$ & $\mathrm{H}_{2} / \mathrm{H}_{2} / \mathbf{H}_{2} \mathbf{O}$ \\
$\mathrm{H}_{2}{ }^{-} / \mathrm{H}_{2} / \mathbf{H}_{2}{ }^{+}$ & $1.00 / 0.06 /-\mathbf{1 4 . 7 1}$ & $-/-/ 2 \mathbf{H}_{2} \mathbf{O}$ \\
$\mathrm{H}_{3}{ }^{-} / \mathrm{H}_{3} / \mathbf{H}_{3}{ }^{+}$ & $2.30 /-2.17 /-\mathbf{1 2 . 9 5}$ & $2 \mathrm{H}_{2} / 2 \mathrm{H}_{2} / \mathbf{H}_{2} \mathbf{O}+\mathbf{H}_{2}$
\end{tabular}

${ }^{a}$ Binding energies are computed using $E_{\mathrm{b}}=E_{\mathrm{p}}-E_{\mathrm{H}}-E_{\mathrm{s}}$, where $E_{\mathrm{p}}$ is the product energy, $E_{\mathrm{H}}$ and $E_{\mathrm{S}}$ energies of the isolated hydrogen containing species and isolated hydroxylated HfN surface. were found to yield volatile $\mathrm{H}_{2}$ products, leaving the surface $-\mathrm{OH}$ groups intact (see ESI section $\mathrm{E} 2 \uparrow$ for the results on fully oxygenated HfN surface).

Based on the energetics results, a set of redox half reactions that likely underlie the binding of $\mathrm{H}^{+}$ions on $\mathrm{Hf}-\mathrm{OH}$ surface groups are proposed and can be found in the ESI (section E3, eqn (S10)-(S14)†). Moreover, we hypothesize that following the liberation of $\mathrm{H}_{2} \mathrm{O}$ from the $\mathrm{HfN}$ surface, $\mathrm{H}^{*}$ radicals in the plasma near the surface restore the pristine HfN surface via reduction of $\mathrm{Hf}(\mathrm{Iv})$ to $\mathrm{Hf}(\mathrm{III})$ in a concerted reaction pathway (eqn (S12) and (S13) $\dagger$ ), in-line with the previously reported XPS results. ${ }^{14}$ This hypothesis is also based on the application of $\mathrm{H}_{2}$ plasma to reduce the $\mathrm{Pt}(\mathrm{Iv})$ and $\mathrm{Ta}(\mathrm{v})$ in the precursor to synthesize metallic Pt(0) and Ta(III)N films with ALD. ${ }^{50,51}$

Based on the experimental observations of the mitigation of oxygen incorporation due to energetic ions, a set of AIMD simulations were designed to probe this effect at molecular level. As aforementioned, the average energy $\left(E_{\text {ion }}\right)$ of the highly-reactive cationic species $\left(\mathrm{H}^{+}, \mathrm{H}_{2}{ }^{+}\right.$and $\left.\mathrm{H}_{3}{ }^{+}\right)$in our experimental work is controlled by the application of external rf substrate bias. ${ }^{13,30}$ In these simulations, the fully hydroxylated HfN surface model (as previously introduced, Fig. S5 $\dagger$ ) was again assumed. In addition, 16 hydrogen cations $\left(\mathrm{H}^{+}\right)$were placed randomly $4.5 \AA$ above the hydroxylated HfN surface in three separate tries (which differ in terms of initial $\mathrm{H}^{+}$positions), and all ions were assigned with the same initial velocities directed towards the surface. A sample simulation model is visualized in Fig. 4a. Two cases with ion velocities of
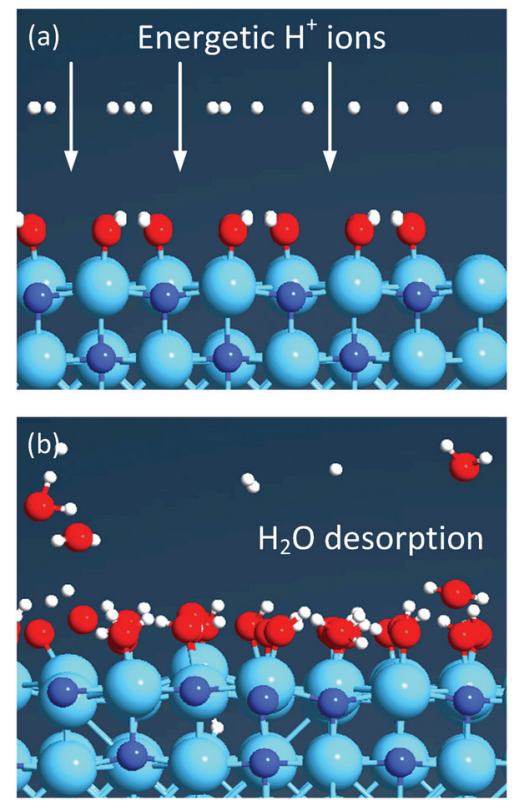

Fig. 4 Ab initio molecular dynamics (AIMD) simulation snapshots illustrating the desorption of $\mathrm{H}_{2} \mathrm{O}$ resulting from the impingement of energetic $\mathrm{H}^{+}$ions with a velocity of $1.75 \AA \mathrm{fs}^{-1}$ on a fully hydroxylated $\mathrm{HfN}$ (200) surface at (a) $\Delta t=0.0$ fs and (b) 350.0 fs. Color code: cyan: Hf; blue: $\mathrm{N}$; red: $\mathrm{O}$; white: $\mathrm{H}$. See ESI section E4, Fig. $\mathrm{S} 6 \dagger$ for additional snapshots of the movies and a real-time video file can be found in the ESI. $\dagger$ 


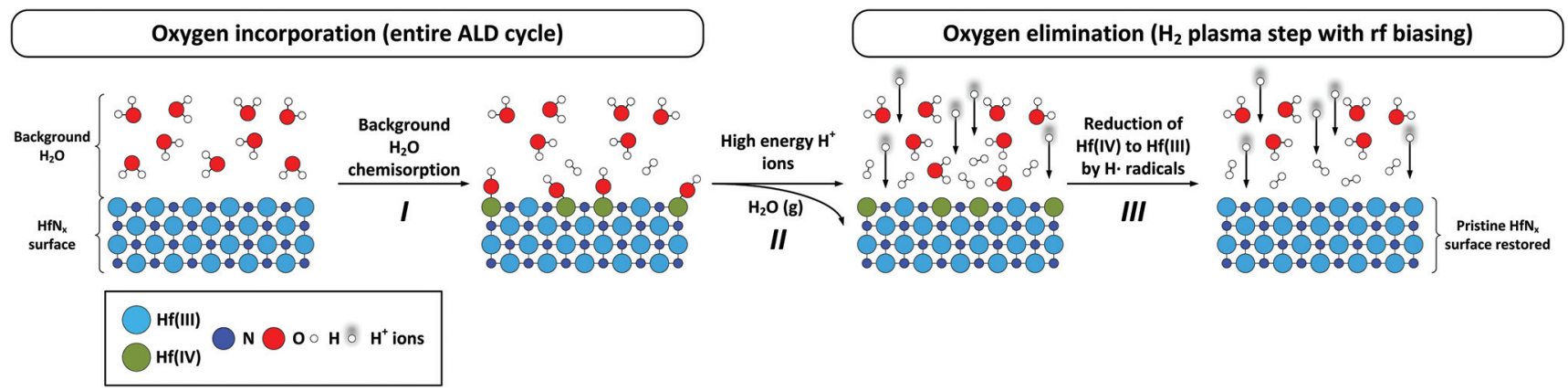

Fig. 5 A schematic summary of the oxygen incorporation and elimination mechanisms proposed in this work. The $\mathrm{H}_{2} \mathrm{O}$ chemisorption occurs during the entire ALD cycle and leads to the hydroxylation of $\mathrm{HfN}$ surface and the formation of $\mathrm{Hf}-\mathrm{OH}$ bonds. The liberation of $\mathrm{H}_{2} \mathrm{O}$ and subsequent reduction of $\mathrm{Hf}(\mathrm{IV})$ to $\mathrm{Hf}(\mathrm{III})$ takes place only during the $\mathrm{H}_{2}$ plasma half cycle, resulting from the impingement of energetic cations. It should be noted that only a part of the entire ALD cycle is depicted.

$\nu_{\mathrm{i}}=0.76 \AA \mathrm{fs}^{-1}$ and $\nu_{\mathrm{i}}=1.75 \AA \mathrm{fs}^{-1}$ were assumed in order to roughly model the resulting kinetic energy for the grounded electrode and rf substrate bias conditions (see ESI section E4, Table $55 \dagger$ for a substantiation of these values). The ions with a lower initial velocity did not lead to dissociation of surface $\mathrm{Hf}-$ $\mathrm{OH}$ bonds. AIMD simulations point at the formation of intermediate surface $\mathrm{Hf}-\left[\mathrm{H}_{2} \mathrm{O}\right]^{+}$species, which remains chemisorbed on the surface, and later dissociates to yield again the $\mathrm{Hf}-\mathrm{OH}$ surface bonds. On the other hand, the ions with a higher initial velocity lead to abstraction of $-\mathrm{OH}$ groups from the surface and $\mathrm{H}_{2} \mathrm{O}$ liberation was observed within the same time frame (e.g. 350 fs simulation) (Fig. 4b). It should also be noted here that the DFT calculations were performed only for the $\mathrm{H}^{+}$ions to limit the computational efforts, however the $\mathrm{H}_{2}^{+}$ and $\mathrm{H}_{3}{ }^{+}$ions are expected to yield similar results.

So far, we have discussed a one-off ion exposure event (i.e. a single layer of ions impacting the surface), while the HfN surface experiences a continuous flux of energetic ions in reality. In an attempt to crudely account for the continuous energetic ion flux, we performed analogous MD simulations with two layers of $16 \mathrm{H}^{+}$ions (instead of one) in the simulation model (with $3.5 \dot{A}$ interlayer separation, data not shown). An extra layer of $\mathrm{H}^{+}$ions with a $\nu_{\mathrm{i}}$ value of $1.75 \dot{\mathrm{A}} / \mathrm{fs}$ indeed led to an increase in the number of removed surface $-\mathrm{OH}$ groups as volatile $\mathrm{H}_{2} \mathrm{O}$ products with respect to a single layer $\mathrm{H}^{+}$ions, thus suggesting an enhanced removal of the surface $-\mathrm{OH}$ groups upon increasing ion flux (see ESI section E5 $\uparrow$ for the discussion on surface termination subsequent to the abstraction of all surface $-\mathrm{OH}$ groups).

\section{Conclusions}

Suppressing the oxygen contamination is a well-known challenge in the synthesis of conductive metal nitride and metal thin films by ALD, since oxygen limits their electrical conductivity. Here, we present a study on the $\mathrm{O}$ incorporation in conductive metal nitrides by using plasma-assisted ALD of $\operatorname{HfN}_{x}$ films as a case study. We investigate the atomic-level processes that lead to the oxidation of the $\operatorname{HfN}_{x}$ surface by first principles DFT calculations. In addition, the kinetics of $\mathrm{O}$ elimination by energetic ions upon application of external rf substrate bias during the $\mathrm{H}_{2}$ plasma step is addressed. The corresponding events of $\mathrm{H}_{2} \mathrm{O}$ chemisorption on the HfN surface and Hf-O bond dissociation and $\mathrm{H}_{2} \mathrm{O}$ formation due to impingement of energetic ions are schematically summarized in Fig. 5.

We show that the $\mathrm{O}$ content in the $\mathrm{HfN}_{x}$ layers is determined by the total flux of $\mathrm{H}_{2} \mathrm{O} / \mathrm{O}_{2}$ impinging on the $\mathrm{HfN}_{x}$ surface during the entire ALD cycle. Next, we observed that an increase in the time-averaged substrate potential from $0 \mathrm{~V}$ to $-130 \mathrm{~V}$ leads to a decrease in the density of Hf-O bonds in $\mathrm{HfN}_{x}$ films due to the impingement of energetic ions.

By using DFT calculations, we found that the chemisorption of $\mathrm{H}_{2} \mathrm{O}$ on the bare $\mathrm{HfN}$ surface is kinetically and thermodynamically highly feasible, creating hydroxyl $(\mathrm{Hf}-\mathrm{OH})$ surface groups (I, Fig. 5). DFT calculations also revealed that only the cationic species $\left(\mathrm{H}^{+}, \mathrm{H}_{2}{ }^{+}, \mathrm{H}_{3}{ }^{+}\right)$present in $\mathrm{H}_{2}$ plasma are highly reactive towards the surface $-\mathrm{OH}$ groups. Moreover, an increase in the energy of incident cations was shown to not only dissociate $\mathrm{Hf}-\mathrm{OH}$ surface bonds but also lead to $\mathrm{H}_{2} \mathrm{O}$ formation and desorption (II, Fig. 5). In addition, the $\mathrm{H}^{*}$ radicals present in $\mathrm{H}_{2}$ plasma are hypothesized to reduce $\mathrm{Hf}(\mathrm{Iv})$ to $\mathrm{Hf}$ (III) subsequent to $\mathrm{H}_{2} \mathrm{O}$ liberation (III, Fig. 5), in line with previously reported increase in $\mathrm{Hf}(\mathrm{III})$ fraction. These reactions can be considered as contributing to a so-called atomic layer cleaning (ALC) process. ${ }^{52}$

In perspective, these results shed light on the mechanism of oxygen incorporation and its mitigation for a wide range of ALD processes, where surfaces with high affinity towards oxidation are considered, such as $\operatorname{TiN}_{x}, \mathrm{HfN}_{x}, \mathrm{MoC}_{x}$, Ta, and enable ALD of low resistivity films with potential application in nano-electronics. ${ }^{10,53,54}$

\section{Conflicts of interest}

All authors have given approval to the final version of the manuscript. There are no conflicts to declare. 


\section{Acknowledgements}

The authors thank Dr Mike Cooke (Oxford Instruments Plasma Technology) for fruitful discussions and Cristian van Helvoirt and Jeroen van Gerwen (University of Technology Eindhoven) for the skilful technical assistance. This work was supported financially by Technologiestichting STW through the project LIMIET (\#13316). Air Liquide is kindly acknowledged for providing the Hf precursor.

\section{Notes and references}

1 J. W. Elam, J. A. Libera, T. H. Huynh, H. Feng and M. J. Pellin, J. Phys. Chem. C, 2010, 114, 17286-17292.

2 S. Haukka, E.-L. Lakomaa, O. Julha, J. Vilhunen and S. Hornytzkyj, Langmuir, 1993, 9, 3497-3506.

3 E. L. Lakomaa, A. Root and T. Suntola, Appl. Surf. Sci., 1996, 107, 107-115.

4 J. Keranen, C. Guimon, E. Iiskola, A. Auroux and L. Niinisto, J. Phys. Chem. B, 2003, 107, 10773-10784.

5 D. Eom, S. Y. No, C. S. Hwang and H. J. Kim, J. Electrochem. Soc., 2006, 153, C229-C234.

6 H. C. M. Knoops, E. M. J. Braeken, K. De Peuter, S. E. Potts, S. Haukka, V. Pore and W. M. M. Kessels, ACS Appl. Mater. Interfaces, 2015, 7, 19857-19862.

7 H. B. R. Lee, W. H. Kim, J. W. Lee, J. M. Kim, K. Heo, I. C. Hwang, Y. Park, S. Hong and H. Kim, J. Electrochem. Soc., 2010, 157, D10-D15.

8 A. Bertuch, B. D. Keller, N. Ferralis, J. C. Grossman and G. Sundaram, J. Vac. Sci. Technol., A, 2017, 35, $01 B 141$.

9 S. Consiglio, W. Zeng, N. Berliner and E. T. Eisenbraun, J. Electrochem. Soc., 2008, 155, H196-H201.

10 T. Faraz, H. C. M. Knoops, M. A. Verheijen, C. A. A. van Helvoirt, S. Karwal, A. Sharma, V. Beladiya, A. Szeghalmi, D. M. Hausmann, J. Henri, M. Creatore and W. M. M. Kessels, ACS Appl. Mater. Interfaces, 2018, 10, 13158-13180.

11 S. B. S. Heil, E. Langereis, F. Roozeboom, M. C. M. Van De Sanden and W. M. M. Kessels, J. Electrochem. Soc., 2006, 153, G956-G965.

12 J. Hinz, A. J. Bauer and L. Frey, Semicond. Sci. Technol., 2010, 25, 075009.

13 S. Karwal, M. A. Verheijen, B. L. Williams, T. Faraz, W. M. M. Kessels and M. Creatore, J. Mater. Chem. C, 2018, 6, 3917-3926.

14 S. Karwal, B. L. Williams, J. P. Niemelä, M. A. Verheijen, W. M. M. Kessels and M. Creatore, J. Vac. Sci. Technol., A, 2017, 35, 01B129.

15 E. J. Kim and D. H. Kim, Electrochem. Solid-State Lett., 2006, 9, C123-C125.

16 J. Y. Kim, D. Y. Kim, H. O. Park and H. Jeon, J. Korean Phys. Soc., 2004, 45, 1639-1643.

17 J. Y. Kim, S. Seo, D. Y. Kim, H. Jeon and Y. Kim, J. Vac. Sci. Technol., As, 2004, 22, 8-12.
18 H. C. M. Knoops, T. Faraz, K. Arts and W. M. M. Kessels, J. Vac. Sci. Technol., A, 2019, 37, 030902.

19 U. Kroll, J. Meier, H. Keppner, A. Shah, S. D. Littlewood, I. E. Kelly and P. Giannoulès, J. Vac. Sci. Technol., A, 1995, 13, 2742-2746.

20 I. Krylov, X. Xu, K. Weinfeld, V. Korchnoy, D. Ritter and M. Eizenberg, J. Vac. Sci. Technol., A, 2019, 37, 010906.

21 E. Langereis, H. C. M. Knoops, A. J. M. MacKus, F. Roozeboom, M. C. M. Van De Sanden and W. M. M. Kessels, J. Appl. Phys., 2007, 102, 083517.

22 J. Musschoot, Q. Xie, D. Deduytsche, S. Van den Berghe, R. L. Van Meirhaeghe and C. Detavernier, Microelectron. Eng., 2009, 86, 72-77.

23 G. Rampelberg, K. Devloo-Casier, D. Deduytsche, M. Schaekers, N. Blasco and C. Detavernier, Appl. Phys. Lett., 2013, 102, 111910.

24 G. B. RaynerJr, N. O’Toole, J. Shallenberger and B. Johs, J. Vac. Sci. Technol., A, 2020, 38, 062408.

25 M. Ritala, M. Leskelä, E. Rauhala and J. Jokinen, J. Electrochem. Soc., 1998, 145, 2914-2920.

26 C. Seungchan, L. Keunwoo, S. Pungkeun, J. Hyeongtag and K. Yangdo, Jpn. J. Appl. Phys., 2007, 46, 4085.

27 M. J. Sowa, Y. Yemane, F. B. Prinz and J. Provine, J. Vac. Sci. Technol., A, 2016, 34, 051516.

28 M. J. Sowa, Y. Yemane, J. Zhang, J. C. Palmstrom, L. Ju, N. C. Strandwitz, F. B. Prinz and J. Provine, J. Vac. Sci. Technol., A, 2017, 35, 01B143.

29 H. C. M. Knoops, K. De Peuter and W. M. M. Kessels, Appl. Phys. Lett., 2015, 107, 014102.

30 H. B. Profijt, M. C. M. Van De Sanden and W. M. M. Kessels, J. Vac. Sci. Technol., A, 2013, 31, 01A106.

31 P. E. Blöchl, Phys. Rev. B: Condens. Matter Mater. Phys., 1994, 50, 17953-17979.

32 G. Kresse and D. Joubert, Phys. Rev. B: Condens. Matter Mater. Phys., 1999, 59, 1758-1775.

33 G. Kresse and J. Furthmüller, Comput. Mater. Sci., 1996, 6, 15-50.

34 G. Kresse and J. Furthmüller, Phys. Rev. B: Condens. Matter Mater. Phys., 1996, 54, 11169-11186.

35 G. Kresse and J. Hafner, Phys. Rev. B: Condens. Matter Mater. Phys., 1993, 47, 558-561.

36 G. Kresse and J. Hafner, Phys. Rev. B: Condens. Matter Mater. Phys., 1994, 49, 14251-14269.

37 P. Hohenberg and W. Kohn, Phys. Rev., 1964, 136, B864B871.

38 W. Kohn and L. J. Sham, Phys. Rev., 1965, 140, A1133A1138.

39 J. P. Perdew, K. Burke and M. Ernzerhof, Phys. Rev. Lett., 1996, 77, 3865-3868.

40 J. P. Perdew, K. Burke and M. Ernzerhof, Phys. Rev. Lett., 1997, 78, 1396-1396.

41 S. Grimme, J. Antony, S. Ehrlich and H. Krieg, J. Chem. Phys., 2010, 132, 154104.

42 P. Sigmund, Phys. Rev., 1969, 184, 383-416.

43 C. Steinbrüchel, Appl. Phys. Lett., 1989, 55, 1960-1962. 
44 S. Sakurai and T. Nakayama, J. Cryst. Growth, 2002, 237239, 212-216.

45 K. J. Kanarik, T. Lill, E. A. Hudson, S. Sriraman, S. Tan, J. Marks, V. Vahedi and R. A. Gottscho, J. Vac. Sci. Technol., A, 2015, 33, 020802.

46 W. Tang, E. Sanville and G. Henkelman, J. Phys.: Condens. Matter, 2009, 21, 084204.

47 R. F. W. Bader, Atoms in Molecules: A Quantum Theory, Oxford University Press, New York, 1990.

48 Comparison of the Bader charges of the bare and hydroxylated $\mathrm{HfN}$ models reveals that the binding of $-\mathrm{OH}$ groups (with a partial charge of $c a .-0.52 e$ per $-\mathrm{OH}$ moiety) triggers a charge transfer away from the surface Hf atoms (amounting to $c a .0 .35 e$ ).
49 M. Sode, T. Schwarz-Selinger and W. Jacob, J. Appl. Phys., 2013, 114, 063302.

50 A. J. M. Mackus, D. Garcia-Alonso, H. C. M. Knoops, A. A. Bol and W. M. M. Kessels, Chem. Mater., 2013, 25, 1769-1774.

51 H. C. M. Knoops, E. Langereis, M. C. M. v. d. Sanden and W. M. M. Kessels, J. Vac. Sci. Technol., A, 2012, 30, 01 A101.

52 T. Faraz, F. Roozeboom, H. C. M. Knoops and W. M. M. Kessels, ECS J. Solid State Sci. Technol., 2015, 4, N5023-N5032.

53 E. Grady, M. Verheijen, T. Faraz, S. Karwal, W. Kessels and A. Bol, arXiv: Applied Physics, 2019.

54 H. Kim and S. M. Rossnagel, Thin Solid Films, 2003, 441, 311-316. 